gaps will now be gradually and methodically filled and redundancies avoided.

So far, "Index Londinensis" covers the period 1753-1920 (inclusive). The earlier literature has been drawn upon only in cases where post-Linnean interpretations have lifted it into the reach of scientific nomenclature. Future studies may give occasion for further additions from this, in many respects, valuable field of botany. However, the gap left by the upward limitation of the records to the year 1920 is far more serious. More than ten years of intense activity have now elapsed. When the original issue of the "Index Kewensis" was completed, its continuation by quinquennial supplements was at once insisted upon and carried out, and their discontinuation could not now be considered, and similar consideration should be given in the case of "Index Londin- ensis". It is already looked upon as the indispensable companion of the "Index Kewensis", and we hope it will remain so. The Royal Horticultural Society has authorised the compilation of a Supplement, intended to take in the pictorial literature for the years 1921-1935 (inclusive), and to be published by the end of 1936 or early in 1937, and it has made an initial grant for one year. The work on the supplement was begun early in 1931 and has so far resulted in a collection of more than 30,000 references, which are now accessible to the student in the Index-room of the Herbarium at Kew. It remains, therefore, to secure the guarantee of such further funds as will be required for the uninterrupted continuation of the work on the basis of, and in conformity with, the main issue, and it is most desirable that provision for this should be made without delay.

\title{
Atmospheric Pollution*
}

$\mathrm{T}^{\mathrm{T}}$ HE seventeenth report on atmospheric pollution issued by the Department for Scientific and Industrial Research records investigations made in Great Britain in the year preceding March 31, 1931. Observations show that the solid matter deposited from the air in twelve months in 42 towns ranges from 550 tons per square mile at one station in Lancashire down to 72 tons in Leicester, the average being more than 200 tons. Generally the observations show a reduction, especially in the sulphates, presumably due to industrial depression and reduced fuel consumption. In London, for some reason, this is not so, and some increases in atmospheric pollution are recorded.

Indeed, the report does not flatter London, which apparently will continue to have its fogs, and the records of suspended impurities do not support the current belief in the decline in the number of smoke fogs. Charing Cross is one of the worst spots, and the amount of smoke haze seems greatly to exceed that of many industrial centres, where the atmosphere by comparison is clean.

The most remarkable records come from Coventry, where on no single day was a smoke haze recorded. Now, Coventry is a large city, highly industrialised, and the circumstances therefore deserve close scrutiny. The Medical Officer advances several reasons to account for this. Coventry is not congested, and has rural surroundings without obstruction to hinder the scavenging action of the wind. The factories are on the outskirts and freely use electricity for power and gas for the heat treatment of metals. Thus there are few sources of industrial smoke, and no special smoke inspection is necessary. Moreover, the use of gas is almost universal in the kitchens there.

It may be urged, however, how will this help in the smoky cities where the heavy trades are practised? For these, the smoke laws have

* Iepartment of scientific and Industrial Research. The Investigation of Atmospheric Pollution: Report on Observations in the Year ended 31 st March 1931. Feventeenth lieport. Pp. vii - 110. (Lon-
don: H.M. Stationery Othce, 1931.) $5 s$. Gil. net. always been lenient and have made no restriction on the emission of black smoke, because of the dogma that steel must be heated in a smoky furnace atmosphere. This should no longer be accepted without challenge. After protracted investigation of the influence of atmosphere on the scaling of steel, Prof. J. W. Cobb and his collaborators at the University of Leeds could not find evidence to support this belief. Indeed, no fuel seems more suitable in this respect for heating steel than a producer gas made from a high temperature coke. Experienced men in the Sheffield trades are not disposed to contest this conclusion, which, if valid, destroys the 'divine right' of the heavy trades to use smoky furnaces, however convenient it may be to do so in practice. Again, steel makers have no objection to using coal gas if the price is right. Any doubt about this is dis. pelled by a journey up the Ruhr Valley in Germany, where coke oven gas is freely used. The comparative cleanness of the atmosphere and the towns there makes a remarkable contrast with corresponding areas in England.

An observant traveller going north from Sheffield may first be shocked by the gross atmospheric pollution he will observe, and in a few minutes amazed by the sight of great flares of coke oven gas - a smokeless fuel-burning to waste. True, this is in process of remedy by the organisation of the South Yorkshire Gas Grid, which now has legal sanction. In general, the law hinders rather than helps the spread of gas. heating in industry, and politicians obsessed with the organisation of electrical supply have done little to assist. In this direction smoke abatement organisations might use their influence.

The report records a study of the proportions of sulphur acids in the London atmosphere, where in foggy weather the quantity of sulphur dioxide may reach one volume per million, although normally it is much less. The work indicates the growing interest in sulphur impurities, the importance of which was emphasised by the tragedy of Liège last winter. It is unlikely that the

No. 3256, VoL. 129] 
absolute quantity of sulphurous impurities is increased by the concentration of power generation in central stations, but the consequences may become more serious for people and property in the immediate neighbourhood. On the other hand, this concentration of power production facilitates the application of processes for the desulphurisation of flue gases. The London Power Company claims to have worked out a practicable process by the use of lime water. Recent patent literature describes a process based on the use of ammonia, which has the merit of producing no intractable liquid effluent. Moreover, ammonia to-day, in the form of gas liquor, is cheap and freely available. It seems fitting that the alkali from coal should be used to neutralise its sulphurous products. However, it can scarcely be doubted that the atmospheric pollution by sulphur due to boiler furnaces can be largely removed when necessary steps are taken.

The report is a voluminous document, containing much interesting matter, both descriptive and tabular. One puts it down with regret that, together with so much knowledge of the problem and its remedy, there should be so little progress towards amelioration.
H. J. HoDsMaN.

\section{Obituary}

DR. E. H. Griffiths, F.R.S.

$\mathrm{D}^{\mathrm{R}}$ R. E. H. GRIFFITHS, formerly principal and professor of physies in the University College of South Wales and Monmouthshire, died, after a long and painful illness, on March 3 , at his residence in Cambridge, in his eighty-first year.

Dr. Griffiths went to Cambridge from Owens College, Manchester, and entered at Sidney Sussex College. He took an ordinary degree in the Applied Science Special in 1873, and shortly afterwards started work as a private tutor, becoming associated with Dr. Campbell, a well-known coach for the examinations in law, and at a later date with the late Mr. C. T. Heycock. In this work he was very successful; pupils of Griffiths and Campbell usually did well in their examinations, and he was soon recognised as one who could be trusted to do his best for a lame dog.

It was not until much later (1889 or 1890) that it was realised that there was a physicist of very marked ability working almost in solitude at the Sidney Laboratory, where Neville and Heycock had been engaged on their well-known metallurgical researches. It was about this time that I first met him, when he came to the Cavendish Laboratory to ask me to standardise a resistance box he was then using-I was in charge of the British Association standards of resistance-and I then learned that he proposed to make what appeared to be a very ambitious attack on the determination of Joule's equivalent, employing the electrical method. To quote his own words from a later paper: "I commenced this work in 1887, and the general principle on which I proposed to proceed was that of eliminating the effects of conduction, radiation, etc., rather than of ascertaining the actual loss or gain due to these causes".

Griffiths' time during the next two years was devoted to preliminary work ; difficulties inherent in the mercury thermometer led him to investigate platinum thermometers and the measurement of platinum temperature as introduced by Callendar in 1886 .

The platinum temperature $p t$ at any temperature $t$ is obtained by measuring the resistance of a wire of platinum. Callendar showed (Phil. Trans. Roy. Soc., A, $161 ; 1887$ ) that the difference, $t-p t$, could be expressed in terms of $p t$ by a formula involving a single coefficient, and at first supposed that this coefficient was the same for all wires of reasonably pure platinum. Griffiths in his paper (Phil. Trans. Roy. Soc., A, 43; 1891) proved that while the formula held with great accuracy, the coefficient varied appreciably from wire to wire - no wire was absolutely pure-so that to standardise a platinum thermometer, a third temperature in addition to the freezing and boiling points of water was required, and in a further paper (Phil. Trans. Roy. Soc., A, 119 ; 1891) Callendar and he communicated an accurate determination of the boiling point of sulphur, and described apparatus for making use of that temperature as a third standardisation point. The platinum thermometer thus became a reliable instrument. In this way means for the accurate measurement of the temperature of the calorimeter were provided, and his real work-the determination of the mechanical equivalent of heat, $J$ could begin, at first in the Sidney Laboratory. Cambridge trams soon made that impossible, and a special building was erected in his own garden.

The investigation described in his paper, "On the Value of the Mechanical Equivalent of Heat " (Phil. Trans. Roy. Soc., A, 361 ; 1893), still constitutes the standard determination by the electrical method. It may be useful to quote the values of $J$ deduced from the results of various experimenters by Griffiths himself in the "Dictionary of Applied Physics", vol. 1, 493; 1922, when reduced to the same units and on the assumption that the e.m.f. of a Clark's cell is I.432 volts :

Capacity for Heat of Water at $20^{\circ}$ (OF the HYDROGEN SCALE)
Rowland, 1878 .
Griffiths, 1893
$4 \cdot 182 \times 10^{7}$
Schuster and Cannon, 1894 .
Callendar and Barnes, 1899 .

$$
\text { Mean }
$$
$4.182 \times 10^{7}$

Any uncertainty in his result depends mainly on the uncertainty attaching to the electrical units of his day, and for the values of these he was dependent on the work in progress at the time at the Cavendish Laboratory.

For some years after this, Griffiths took an active part in discussions at the British Association and 